\title{
Bone morphogenetic protein and activin membrane-bound inhibitor suppress bone cancer progression in MG63 and SAOS cells via regulation of the TGF- $\beta$-induced EMT signaling pathway
}

\author{
FENGSONG LIU, KAI WANG, LIANG ZHANG and YA-LIN YANG \\ Department of Orthopedics, The Second Hospital of Tianjin Medical University, Tianjin 300211, P.R. China
}

Received July 15, 2017; Accepted May 30, 2018

DOI: $10.3892 / \mathrm{ol} .2018 .9268$

\begin{abstract}
Bone cancer is one of the most common tumor types that occurs in bones and their affiliated tissues. The prognosis remains poor due to the limited number of effective therapeutic targets. Downregulation of bone morphogenetic protein and activin membrane-bound inhibitor (BAMBI) has been observed in human cancer cells and BAMBI reconstitution can inhibit growth and metastasis of human cancer cells. In the present study, a potential mechanism mediated by BAMBI in osteosarcoma cells was investigated. The data demonstrated that BAMBI reconstitution suppressed the cell growth, migration and invasion of the osteosarcoma cell lines SAOS2 and MG63. Alterations to the epithelial-to-mesenchymal transition (EMT) marker expression were observed in BAMBI-treated osteosarcoma SAOS2 and MG63 cells. The apoptosis rate of SAOS2 and MG63 cells induced by cisplatin were increased in BAMBI-treated osteosarcoma SAOS2 and MG63 cells via downregulation of the anti-apoptosis genes P16, P21 and B-cell lymphoma 2. The potential mechanism investigated indicated that BAMBI administration downregulated the transforming growth factor- $\beta$ (TGF- $\beta$ ) signaling pathway, whilst knockdown of BAMBI upregulated the TGF- $\beta$ signaling pathway in SAOS2 and MG63 cells. Reconstitution of BAMBI in SAOS2 and MG63 cells resulted in a notable reduction of TGF- $\beta$-induced EMT, cell growth, migration and invasion in vitro. In conclusion, the results demonstrated that BAMBI reconstitution inhibited growth and invasiveness of osteosarcoma, as well as promoted the apoptotic sensibility, which indicated that the TGF- $\beta$-induced EMT signaling pathway may be regarded as a potential target for osteosarcoma therapy.
\end{abstract}

Correspondence to: Dr Kai Wang or Dr Ya-Lin Yang, Department of Orthopedics, The Second Hospital of Tianjin Medical University, 23 Pingjiang Road, Tianjin 300211, P.R. China

E-mail: 13920574233@139.com

E-mail: yangyalingdoctor@163.com

Key words: osteosarcoma, bone morphogenetic protein and activin membrane-bound inhibitor, transforming growth factor- $\beta$ /epithelial-to-mesenchymal transition, growth, invasion

\section{Introduction}

Osteosarcoma is a malignant tumor, which caused the most cancer-associated mortalities in Asia during the early 21st century; however, the prognosis remains poorly understand (1-3). The symptoms of osteosarcoma include: Tumor pain, caused by tumor tissue erosion; and dissolved bone cortex (3). Increasing the apoptosis of osteosarcoma cells induced by anticancer drugs has become a challenge in cancer therapy due to tumor cell resistance via various signaling pathways $(4,5)$. Recently, numerous strategies, with the aim of decreasing apoptotic resistance, have been proposed and indicated that the overall survival rate for patients with osteosarcoma can be improved, based on clinical statistical analysis $(6,7)$; therefore, understanding the mechanism underlying apoptotic resistance and efficacy target therapy is urgently required to improve the overall survival rate for patients with osteosarcoma.

Bone morphogenetic protein and activin membrane-bound inhibitor (BAMBI) is a pseudo-receptor of SMAD7 and is homologous to transforming growth factor- $\beta$ receptor 1 (TGF- $\beta$ R1), which lacks the functional domain for an active kinase $(8,9)$. BAMBI is also regarded as a TGF- $\beta$ pseudo-receptor and participates in the regulation of the TGF- $\beta$-mediated signaling pathway in various cancer types, including bladder, colorectal, ovarian, non-small cell lung (NSCLC) and gastric cancer (10-13). Additionally, BAMBI overexpression is beneficial for suppressing the growth and metastasis of gastric cancer cells by inhibiting the $\beta$-catenin and TGF- $\beta$ signaling pathways (14). Furthermore, research has demonstrated that downregulation of the TGF- $\beta$ pseudo-receptor BAMBI in NSCLC promotes the TGF- $\beta$ signaling pathway, which further promotes the growth and invasion of lung cancer tissues (15). These reports indicated that BAMBI may be involved in the progression of human cancer.

In the present study, it was reported that BAMBI is downregulated in osteosarcoma cells and upregulation of the TGF- $\beta$ pseudo-receptor BAMBI significantly inhibited the growth, proliferation, migration, invasion and resistance to apoptosis of osteosarcoma cells. The data indicated that BAMBI has critical oncolytic effects on osteosarcoma progression and demonstrated the therapeutic role for the treatment of osteosarcoma in vitro and in vivo. 


\section{Materials and methods}

Ethics statement. The present preclinical study was performed according to the recommendations in the Guide for the Care and Use of Laboratory Animals of China (16). All experimental protocols and animals were approved by the Committee on the Ethics of Animal Experiments Defence Research of the Second Hospital of Tianjin Medical University (Tianjin, China). Clinical samples were collected from The Second Hospital of Tianjin Medical University (Tianjin, China). All patients were required to write informed consent with a signature. The study was approved by the Ethics Committee of The Second Hospital of Tianjin Medical University (Tianjin, China). A total of 60 patients with osteosarcoma (27 males, 33 females; age range, 22-61 years; median age, 49 years) between July 2013 and March 2017 were recruited into the present study.

Cells and reagents. Osteosarcoma cell lines SAOS2 and MG63 cells and human normal osteoblast hFOB1.19 cells were purchased from American Type Culture Collection (Manassas, VA, USA). SAOS2 and MG63 cells were cultured in Dulbecco's modified Eagle's medium (Gibco; Thermo Fisher Scientific, Inc., Waltham, MA, USA) supplemented with $10 \%$ fetal bovine serum (FBS; Invitrogen; Thermo Fisher Scientific, Inc.). hFOB1.19 cells were cultured in RPMI-1640 (Sigma-Aldrich; Merck KGaA, Darmstadt, Germany) medium supplemented with $10 \%$ fetal calf serum (Gibco; Thermo Fisher Scientific, Inc.). All cells were cultured in a $37^{\circ} \mathrm{C}$ humidified atmosphere containing $5 \% \mathrm{CO}_{2}$.

Reverse transcription quantitative-polymerase chain reaction (RT-qPCR). Total RNA was extracted from SAOS2, MG63 and hFOB1.19 cells using a RNAeasy Mini kit (Qiagen Sciences, Inc., Gaithersburg, MD, USA). A total of $1 \mu \mathrm{g}$ total RNA was used to transcribe into cDNA by using the PrimeScript RT Master Mix (Qiagen Sciences, Inc.) according to the manufacturer's protocol. The cDNA (10 ng) was subjected to RT-qPCR with SYBR Green Master Mix system (Bio-Rad Laboratories, Inc., Hercules, CA, USA). All the forward and reverse primers were synthesized by Invitrogen (Thermo Fisher Scientific, Inc.). For the PCR experiments, the following forward and reverse primers were used: Caspase-3, forward, 5'-TGGCAGCAGTGACAGCAGCA-3' and reverse, 5'-TACGGAGGTGGAGTGGGTGT-3'; caspase-8, forward, 5'-AGCCGAGGA AGA ACTATGAAC-3' and reverse, 5'-ATTTGAGGGTGAGGAATGGG-3'; P16, forward, 5'-GAG GGCAGAATCATCACGAAGT-3' and reverse, 5'-TGAGAG ATCTGGTTCCCGAAAC-3'; P21, forward, 5'-AGGCAC GAGTAACAAGCTCAC-3' and reverse, 5'-ATGAGGACA TAACCAGCCACC-3'; Bcl-2, 5'-GTGGACATCCGCAAA GAC-3' and reverse, 5'-AAAGGGTGTAACGCAACTA-3'; BAMBI, forward, 5'-AGGCACGAGTAACAAGCTCAC-3' and reverse, 5'-ATGAGGACATAACCAGCCACC-3'; Bcl-2, 5'-AAGGAATTTGTAACAAAGGT-3' and reverse, 5'-AGA CCTGTGAGATGACCTCC-3'; and reference gene GAPDH, forward 5'-GTGGGCGCCCAGGCACCA-3' and reverse, 5'-CTCCTTAATGTCACGCACGATTT-3'. Amplification conditions consisted of $5 \mathrm{sec}$ of denaturation at $94^{\circ} \mathrm{C}, 9 \mathrm{sec}$ of annealing at $55-60^{\circ} \mathrm{C}$ and $9 \mathrm{sec}$ of extension at $72^{\circ} \mathrm{C}$, for 45 cycles for each step. Relative mRNA expression changes were calculated by $2^{-\Delta \Delta C q}(17)$. The results are expressed as the relative expression compared with control.

MTT assays. SAOS2 and MG63 cells were treated with BAMBI $(0,5,10$ and $15 \mathrm{mg} / \mathrm{ml}$, Abcam, Cambridge, UK) or PBS and cultured in 96-well plates for $48 \mathrm{~h}$. A total of $20 \mu \mathrm{l}$ MTT ( $5 \mathrm{mg} / \mathrm{ml})$ in PBS solution was added to each well, and the plate was further incubated for $4 \mathrm{~h}$ at $37^{\circ} \mathrm{C}$. The medium was removed and $100 \mu 1$ dimethyl sulfoxide (Sigma-Aldrich; Merck KGaA) was added into the wells to solubilize the crystals. The OD was measured by an iMark microplate absorbance reader (Bio-Rad Laboratories, Inc.) at wavelength of $450 \mathrm{~nm}$.

TGF- $\beta$ overexpression ( $p T G F-\beta$ ). TGF- $\beta$ gene was cloned into a PMD-18-T vector and sequenced to identify its sequence, according to a previous report (18). The TGF- $\beta$ gene was then cloned into a eukaryotic expression vector pCMVp-NEO-BAN (pTGF- $\beta$; Takara Biotechnology Co., Ltd, Dalian, China) to generate TGF- $\beta$-overexpressed SAOS2 or MG63 cells as described previously (18). SAOS2 and MG63 cells were cultured in 6-well plates in RPMI-1640 medium containing 10\% FBS at $37^{\circ} \mathrm{C}$ until $90 \%$ confluence and the media was then removed. SAOS2 and MG63 $\left(5 \times 10^{6}\right)$ cells were transfected with pTGF- $\beta$ $(1.0 \mu \mathrm{g}$, Takara Biotechnology Co.) or pvector $(1.0 \mu \mathrm{g})$ using Lipofectamine ${ }^{\circledR} 2000$ (Thermo Fisher Scientific, Inc.), according to the manufacturer's protocol. Stable TGF- $\beta$-overexpression SAOS2 or MG63 cells were selected using the dihydrofolate reductase/glutamine synthetase (Invitrogen; Thermo Fisher Scientific, Inc.) screening system (19).

Terminal deoxynucleotidyl transferase-mediated dUTP nick end labeling (TUNEL) assay analysis. For analysis of the apoptosis of osteosarcoma, a TUNEL assay (Beyotime Institute of Biotechnology, Haimen, China) was used to detect TUNEL-positive cells. Tumor sections isolated from xenografted mice were fixed with $4 \%$ paraformaldehyde solution for $60 \mathrm{~min}$ at $4^{\circ} \mathrm{C}$. The tumor tissues were washed with PBS three times and then permeabilized by immersing cells slides in $0.2 \%$ Triton X-100 solution in PBS for 30 min at $4^{\circ} \mathrm{C}$. Subsequently, tumor tissues were incubated with equilibration buffer (Beyotime Institute of Biotechnology) for $30 \mathrm{~min}$ at $4^{\circ} \mathrm{C}$. The tumor tissues were then incubated with $50 \mu 1$ reaction mixture (Beyotime Institute of Biotechnology) at $37^{\circ} \mathrm{C}$ for 60 min and washed 3 times with PBS. These sections were incubated in 5\% bovine serum albumin (BSA) for $30 \mathrm{~min}$ and the fragmented DNA was labeled with the TUNEL reaction solution at $37^{\circ} \mathrm{C}$ for $1 \mathrm{~h}$. Hoechst $33258(5 \mathrm{mg} / \mathrm{l} ; \mathrm{H}-33258$; Sigma-Aldrich; Merck KGaA) was used to stain the nuclei for $10 \mathrm{~min}$ at room temperature. Converter-peroxidase was added to the sections at $37^{\circ} \mathrm{C}$ for $30 \mathrm{~min}$ prior to the TUNEL-positive nuclei being visualized by adding the DAB staining solution. Finally, tumor tissues images were captured with a confocal microscope at $488 \mathrm{~nm}$. TUNEL-positive cells were counted in 5 randomly selected fields per section. The apoptosis rate was expressed as the ratio of TUNEL-positive cardiomyocytes to the total number of cardiomyocytes.

Apoptotic detection. SAOS2 and MG63 cells were cultured in RPMI-1640 medium containing $10 \% \mathrm{FBS}$ at $37^{\circ} \mathrm{C}$ until $90 \%$ confluence and then treated with BAMBI $(10 \mathrm{mg} / \mathrm{ml})$. Cells 
were continually cultured for $48 \mathrm{~h}$ at $37^{\circ} \mathrm{C}$ and then trypsinized, collected and washed in cold PBS 3 times. Subsequently, the cells $\left(1 \times 10^{6}\right.$ cells $\left./ \mathrm{ml}\right)$ were mixed with PBS, labeled with Annexin V-fluorescein isothiocyanate (FITC) and propidium iodide (Annexin V-FITC kit; BD, San Diego, CA, USA) according to the manufacturers protocol and analyzed with a FACScan flow cytometer (BD Biosciences, San Jose, CA, USA) and Quantity One software (version 3.0; Bio-Rad Laboratories, Inc.).

Cells invasion and migration assays. SAOS2 and MG63 cells were treated with BAMBI $(5 \mathrm{mg} / \mathrm{ml})$ for $24 \mathrm{~h}$ at $37^{\circ} \mathrm{C}$ and used to analyze the cell invasion and migration. SAOS2 and MG63 cells were placed in a 24-well culture plate with chamber inserts (BD Biosciences). For migration assays, 5x10 $/$ well SAOS2 and MG63 cells in RPMI-1640 medium were placed into the upper chamber with the non-coated membrane at $37^{\circ} \mathrm{C}$ for $24 \mathrm{~h}$. For invasion assays, the cells $\left(5 \times 10^{4} /\right.$ well $)$ were placed into the upper chamber with the Matrigel-coated membrane. In the invasion assay, cells were treated with BAMBI $(5 \mathrm{mg} / \mathrm{ml})$ for $24 \mathrm{~h}$ and subjected to the tops of BD BioCoat Invasion Chambers (BD Biosciences), according to the manufacturer's protocols. The medium and serum in the lower chamber was DMEM plus 20\% FBS. The number of tumor cells that invaded and migrated through the membrane were by stained with $0.5 \%$ crystal violet at $37^{\circ} \mathrm{C}$ for $30 \mathrm{~min}$ and counted at least three randomly selected fields per membrane under a light microscope in five random visual fields (magnification, x200).

Western blot analysis. SAOS2 and MG63 cells were treated with SB431542 (5 ng/ml, cat. no 93-1674-1; Biovision Inc., Milpitas, CA, USA), cisplatin (10 mg/ml, Takara Biotechnology Co.,Ltd.) and BAMBI (10 mg/ml) and harvested by scraping and lysed in radioimmunoprecipitation assay buffer (Invitrogen; Thermo Fisher Scientific, Inc.) followed by homogenization at $4^{\circ} \mathrm{C}$ for $10 \mathrm{~min}$. Protein concentration was calculated using a BCA protein assay kit (Thermo Fisher Scientific, Inc.). Proteins (10 $\mu \mathrm{g})$ were analyzed via 10\% SDS-PAGE assays, followed by transferring onto polyvinylidene fluoride membrane. Proteins were then blocked with 5\% BSA (Sigma-Aldrich; Merck $\mathrm{KGaA}$ ) for $2 \mathrm{~h}$ at $37^{\circ} \mathrm{C}$ and incubated for $1 \mathrm{~h}$ at room temperature with primary rabbit anti-mouse antibodies against: BAMBI (1:500; cat. no. AF2387; R\&D Systems, Inc., Minneapolis, USA); P21 (1:1,000; cat. no. ab109199; Abcam); P16 (1:1,000; cat. no. ab51243; Abcam); B-cell lymphoma 2 (1:1,000; Bcl-2; cat. no. ab692; Abcam); TGF- $\beta$ (1:1,000; cat. no. AF532; R\&D Systems); epithelial (E)-cadherin (1:200; cat. no. NBP238856; Novus Biologicals LLC, Littleton, CO, USA); vimentin (1:500; cat. no. PAB24865; Abnova, Taipei, Taiwan); Twist (1:500; cat. no. DR1088100UG; EMD Millipore, Billerica, MA, USA); Smad2 (1:500; cat. no. ab53110; Abcam); Smad3 (1:500; cat. no. ab40854; Abcam); caspase-3 (1:500; cat. no. ab13847; Abcam); caspase-8 (1:500; cat. no. ab25901; Abcam); pSMAD2 (1:500; cat. no. ab53100; Abcam); pSMAD3 (1:500; cat. no. ab63403; Abcam) and $\beta$-actin (1:500; cat. no. ab8226; Abcam). Subsequently, proteins were inoculated with rabbit horseradish peroxidase (HRP)-labeled IgG (1:10,000; cat. no. ab6728; Abcam) for $12 \mathrm{~h}$ at $4^{\circ} \mathrm{C}$. The proteins expression levels were visualized using a chemiluminescence detection system (Nikon Corporation, Tokyo, Japan). Expression levels were determined relative to $\beta$-actin. The density of the bands was analyzed using Quantity One software version 4.62 (Bio-Rad Laboratories, Inc.). Protein expression was analyzed using BandScan 5.0 software (Glyko, Inc., Novato, CA, USA). All experiments were repeated $\geq 3$ times.

Immunohistochemistry. Tumors from Mg63-bearing xenograph mice were fixed using $10 \%$ formaldehyde followed with being embedded in paraffin wax and cut into serial sections of $4 \mu \mathrm{m}$ thickness. Paraffin-embedded tissue sections $4 \mu \mathrm{m}$ thick were prepared and epitope retrieval was performed for further analysis. The paraffin sections were incubated with hydrogen peroxide (3\%) for $10-15 \mathrm{~min}$ at $37^{\circ} \mathrm{C}$ and were subsequently blocked with a regular blocking solution (normal goat serum) for $10-15 \mathrm{~min}$ at $37^{\circ} \mathrm{C}$. Tumor sections were incubated with primary antibodies against: TGF- $\beta$; E-cadherin; vimentin; and Twist. Subsequently, proteins were inoculated with rabbit HRP-labeled IgG (1:5,000; cat. no. ab6728, Abcam) for $12 \mathrm{~h}$ at $4^{\circ} \mathrm{C}$. Specimens were visualized. Images were captured using fluorescence video microscopy (BZ-9000; Keyence Corporation, Osaka, Japan) at x400 magnification. A Benchmark automated staining system (Ventana Medical Systems, Inc, Tucson, AZ USA) was used for observation of integrin.

Animal study. Specific pathogen-free female nude (six-eight weeks old, 25-32 g) C57BL/6 mice were purchased from Shanghai Slack Experimental Animals Co., Ltd. (Shanghai, China). All mice were housed at room temperature with a 12/12 h light/dark cycle and fed ad libitum. Mouse breeding and experiments were carried out under the Institutional Animal Care and Use Committee approved protocols of Ethics Committee of Library Animals (16). Mg63 tumor cells $\left(1 \times 10^{7}\right)$ were subcutaneously implanted into the right flank of C57BL/6 mice ( $n=60)$. Mice bearing osteosarcoma were randomly divided into two groups ( $\mathrm{n}=30$ in each group) and received treatment with BAMBI $(10 \mathrm{mg} / \mathrm{kg})$ or PBS. The treatments for tumor-bearing mice were initiated when tumor diameters reached 5-7 $\mathrm{mm}$ on day 3 following tumor inoculation. The detail procedures were referenced according to previous report (20). The treatments were continued seven times at intervals of every two days. Tumor diameters were recorded every two days and tumor volume was calculated using the formula: $0.52 \mathrm{x}$ smallest diameter ${ }^{2} \mathrm{x}$ largest diameter (21). The experimental mice were euthanized when tumor diameter reached $10 \mathrm{~mm}$ with $1 \%$ pentobarbital $(200 \mathrm{mg} / \mathrm{kg})$ administered via intravenous injection. On day 25, 10 mice in each group were sacrificed for further analysis, including immunohistochemistry.

Statistical analysis. All data are presented as the mean \pm standard error of the mean of triplicate experiments. Unpaired data was determined by Student's t-test and comparisons of data between multiple groups were analyzed by analysis of one-way analysis of variance followed by Fisher's Least Significant Difference post hoc test. Kaplan-Meier analysis was used to estimate the risk of relapse and re-treatment during the 100-day treatment. All data analysis was performed using SPSS software (version 20.0; IBM Corp., Armonk, NY, USA). P<0.05 was considered to indicate a statistically significant difference. 
A

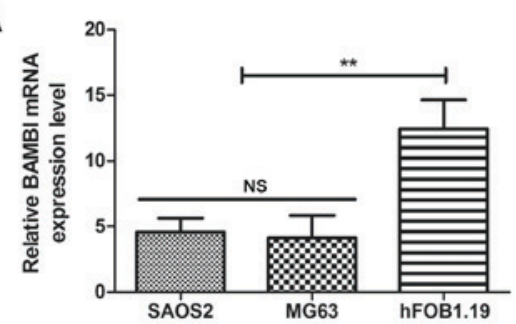

C

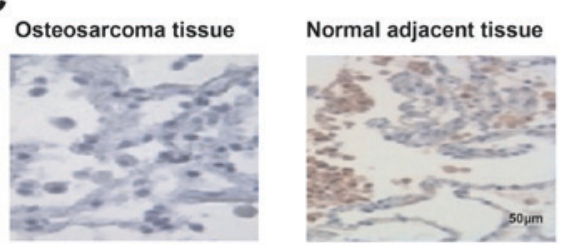

B

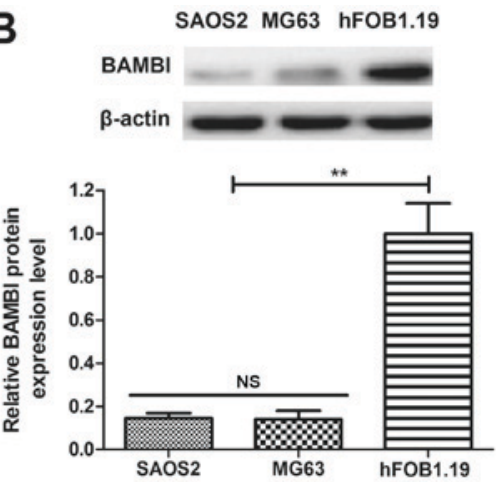

D

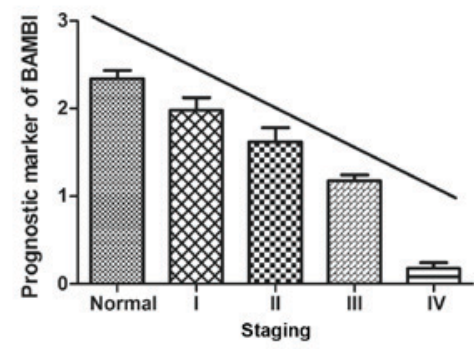

Figure 1. Analysis of BAMBI expression in osteosarcoma cell lines and clinical tumor tissues. Analysis of (A) mRNA and (B) protein expression levels of BAMBI in SAOS2 and MG63 cells, compared with normal cell line hFOB1.19. (C) BAMBI is downregulated in osteosarcoma tissues, compared with normal adjacent tissues (magnification, x200). (D) Analysis of BAMBI expression and prognostic markers in osteosarcoma. ${ }^{* *} \mathrm{P}<0.01 \mathrm{vs.} \mathrm{control} \mathrm{group.} \mathrm{NS,} \mathrm{no}$ significant differences; BAMBI, bone morphogenetic protein and activin membrane-bound inhibitor.

A

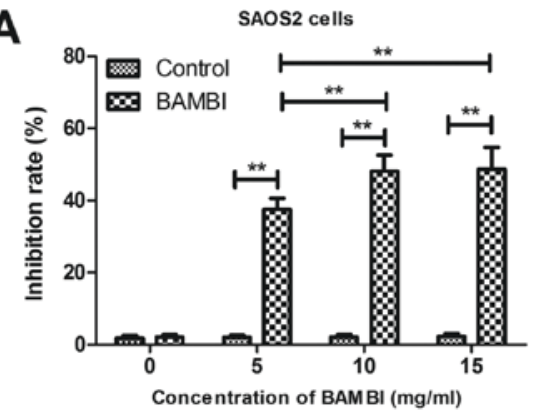

C
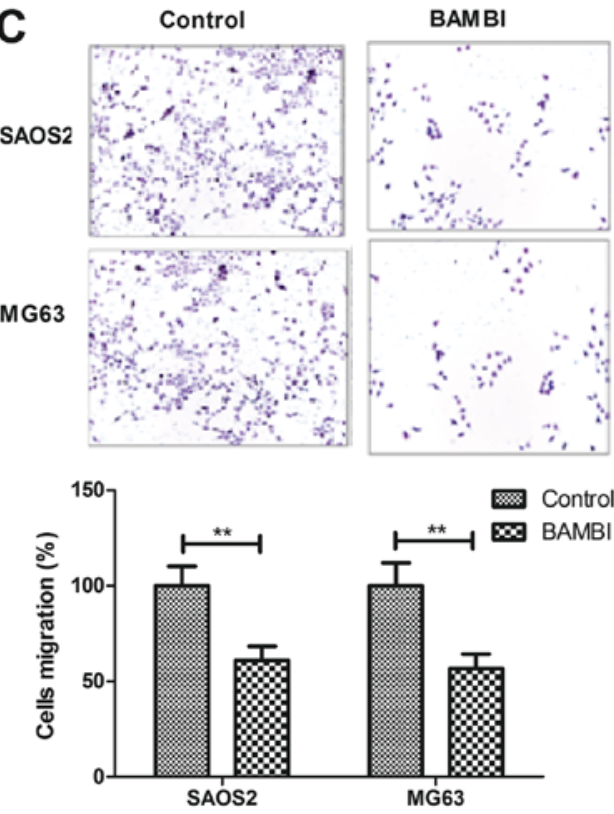

B

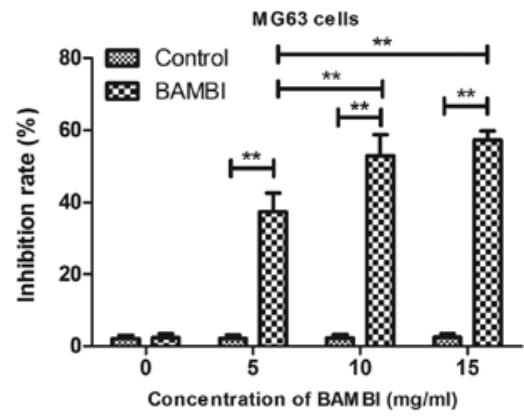

D
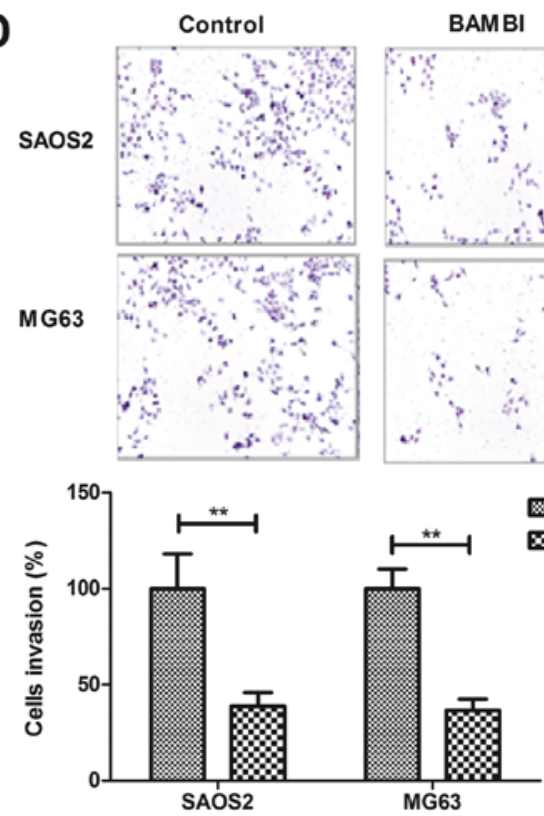

Figure 2. BAMBI suppresses the growth and aggressiveness of osteosarcoma cell lines. BAMBI treatment inhibited (A) SAOS2 and (B) MG63 cell growth in a dose-dependent manner. BAMBI (10 mg/ml) treatment suppressed (C) migration and (magnification, x200). (D) Invasion of SAOS2 and MG63 cells. BAMBI, bone morphogenetic protein and activin membrane-bound inhibitor. ${ }^{* *} \mathrm{P}<0.01$ vs. control group. 

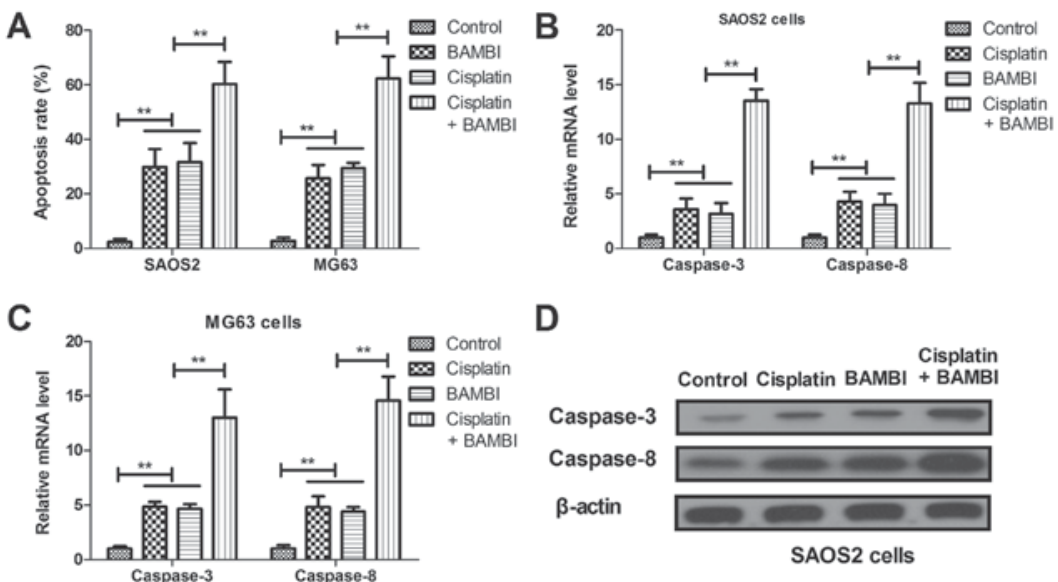

D
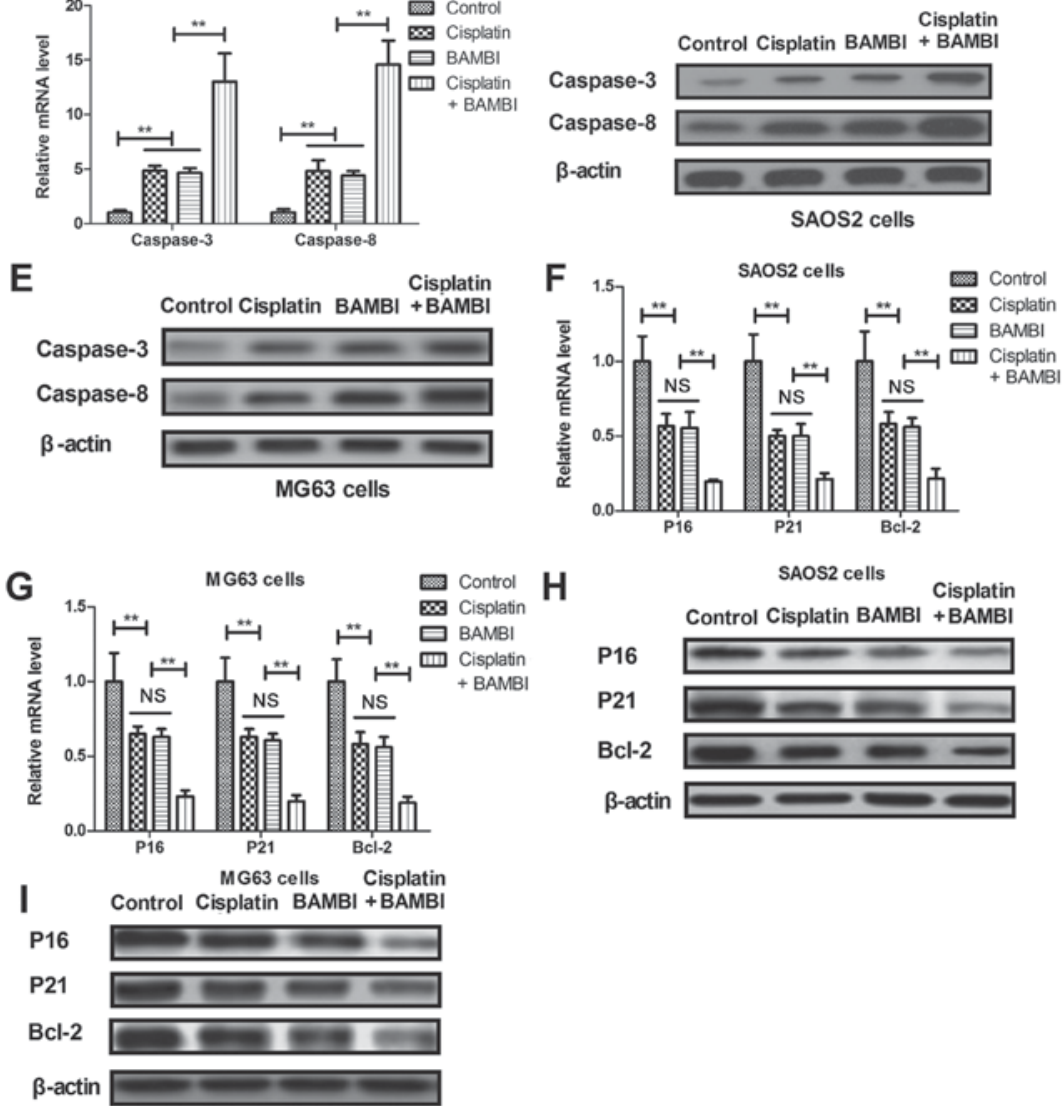

Figure 3. BAMBI promotes apoptosis of osteosarcoma cells induced by cisplatin. (A) BAMBI $(10 \mathrm{mg} / \mathrm{ml})$ promoted the apoptosis of SAOS2 and MG63 cells induced by cisplatin. BAMBI (10 mg/ml) increased caspase- 3 and caspase- 8 gene expression in (B) SAOS2 and (C) MG63 cells. BAMBI (10 mg/ml) increased caspase-3 and caspase-8 protein expression in (D) SAOS2 and (E) MG63 cells. BAMBI (10 mg/ml) decreased the anti-apoptosis genes P16, P21 and Bcl-2 in (F) SAOS2 and (G) MG63 cells. BAMBI (10 mg/ml) decreased the anti-apoptosis proteins P16, P21 and Bcl-2 in (H) SAOS2 and (I) MG63 cells. BAMBI, bone morphogenetic protein and activin membrane-bound inhibitor; Bcl-2, B-cell lymphoma $2 .{ }^{* *} \mathrm{P}<0.01$ vs. control group.

\section{Results}

BAMBI expression is downregulated in osteosarcoma cell lines. Expression levels of BAMBI in osteosarcoma cell lines and clinical tumor tissues were analyzed. It was observed that mRNA and protein expression levels of BAMBI were upregulated in SAOS2 and MG63 cells, compared with normal cell line hFOB1.19 (Fig. 1A and B). It was also determined that BAMBI expression levels were lower in osteosarcoma tissues, compared with normal adjacent tissues, determined by immunohistochemistry (Fig. 1C). Results in Fig. 1D indicated that BAMBI expression may be an independent prognostic marker in osteosarcoma, as demonstrated by multivariate analyses. Collectively, these results indicated that BAMBI downregulation may be associated with osteosarcoma progression.

BAMBI reconstitution $(10 \mathrm{mg} / \mathrm{ml})$ suppresses growth and aggressiveness of osteosarcoma cell lines. In order to analyze inhibitory effects of BAMBI on osteosarcoma cell growth and aggressiveness of SAOS2 and MG63 cells, BAMBI was added into cultured osteosarcoma cells. As depicted in Fig. 2A and B, BAMBI treatment significantly inhibited SAOS2 and MG63 cells growth in a dose-dependent manner $(\mathrm{P}<0.05)$. BAMBI $(10 \mathrm{mg} / \mathrm{ml})$ treatment was observed to notably suppress the migration and invasion of SAOS2 and MG63 cells after $24 \mathrm{~h}$ incubation (Fig. 2C and D). Collectively, the data indicated that BAMBI treatment inhibited the growth and aggressiveness of osteosarcoma cells in vitro.

BAMBI reconstitution promoted apoptosis of osteosarcoma cells induced by cisplatin. Apoptosis of osteosarcoma cell lines SAOS2 and MG63 was investigated following treatment with cisplatin $(10 \mathrm{mg} / \mathrm{ml})$. As depicted in Fig. 3A, BAMBI $(10 \mathrm{mg} / \mathrm{ml})$ promoted the apoptosis of SAOS2 and MG63 cells induced by cisplatin, compared with non-treated cells. RT-qPCR demonstrated that gene and protein 
A
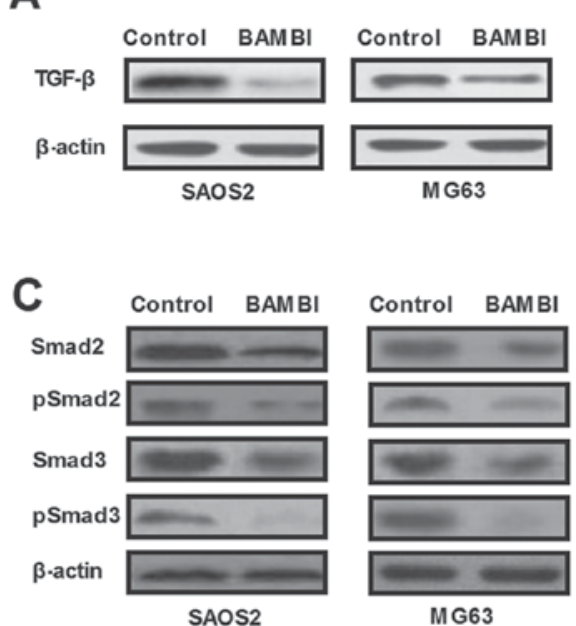

E
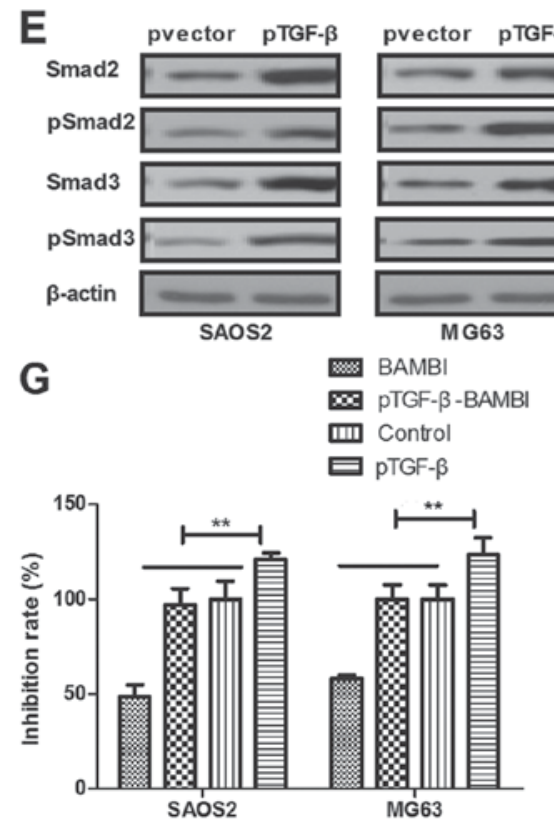

B

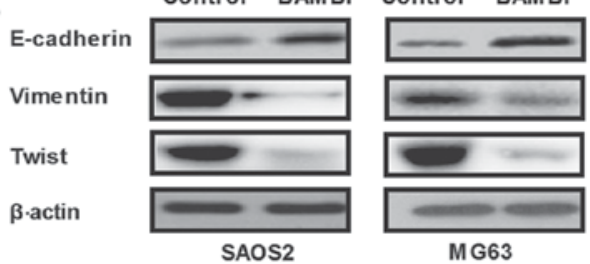

D

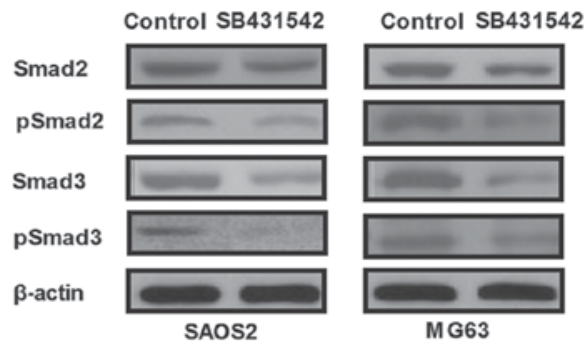

$\mathbf{F}$

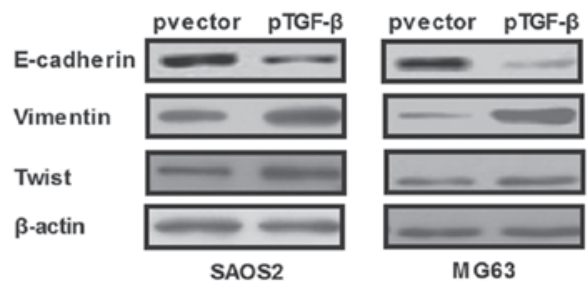

H
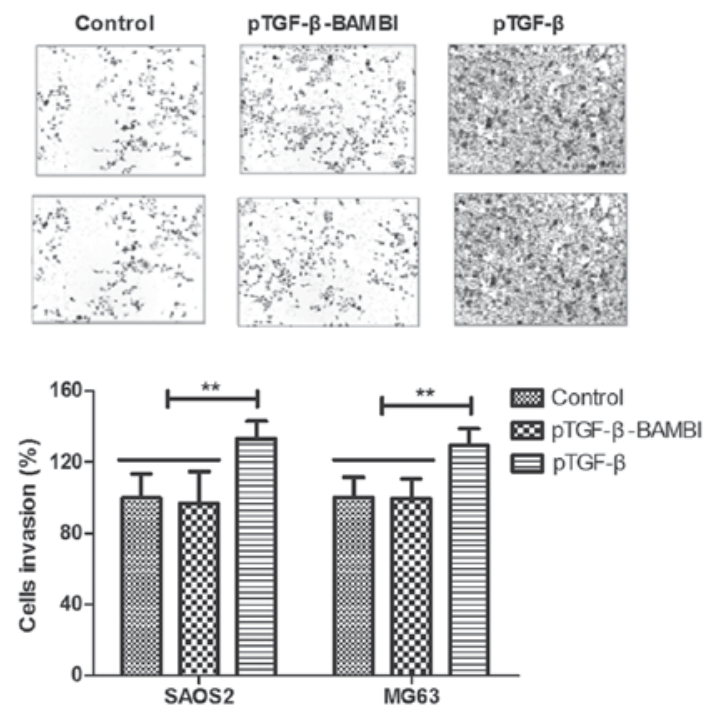

Figure 4. BAMBI inhibits osteosarcoma growth and invasion via the TGF- $\beta$-induced EMT signaling pathway. (A) BAMBI treatment suppressed TGF- $\beta$ protein expression in SAOS2 and MG63 cells. (B) BAMBI treatment inhibited EMT markers E-cadherin, vimentin and Twist expression in SAOS2 and MG63 cells. (C) BAMBI treatment inhibited the expression and phosphorylation levels of Smad2 and Smad3 in SAOS2 and MG63 cells. (D) TGF- $\beta$ receptor using SB431542 suppressed the expression and phosphorylation levels of Smad2 and Smad3 in SAOS2 and MG63 cells. (E) pTGF- $\beta$ antagonized the downregulated expression and phosphorylation of Smad2 and Smad3 in SAOS2 and MG63 cells. (F) pTGF- $\beta$ increased EMT markers expression in BAMBI-treated SAOS2 and MG63 cells. pTGF- $\beta$ inhibited the BAMBI-inhibited (G) growth and (H) invasion of SAOS2 and MG63 cells (magnification, $x 200$ ). pTGF- $\beta$, TGF- $\beta$ overexpression; E-cadherin, epithelial-cadherin; BAMBI, bone morphogenetic protein and activin membrane-bound inhibitor; TGF- $\beta$, transforming growth factor- $\beta$; EMT, epithelial-to-mesenchymal transition. ${ }^{* *} \mathrm{P}<0.01$ vs. control group.

expression levels of caspase-3 and caspase- 8 were upregulated in BAMBI-treated SAOS2 and MG63 cells (Fig. 3B-E). It was demonstrated that anti-apoptosis gene and protein expression levels of P16, P21 and Bcl-2 were decreased in SAOS2 and MG63 following BAMBI treatment $(10 \mathrm{mg} / \mathrm{ml})$, compared with the control (Fig. 3F-I). Collectively, these results indicated that BAMBI promotes apoptosis of osteosarcoma cells induced by cisplatin.
BAMBI inhibits osteosarcoma growth and invasion via the TGF- $\beta$-induced EMT signaling pathway. In order to investigate the potential mechanism underlying BAMBI-mediated inhibition of growth and aggressiveness in osteosarcoma cell lines, the TGF- $\beta$-induced EMT signaling pathway in SAOS2 and MG63 cells was analyzed. As depicted in Fig. 4A, BAMBI treatment suppressed TGF- $\beta$ protein expression in SAOS2 and MG63 cells. Additionally, BAMBI treatment increased 
A

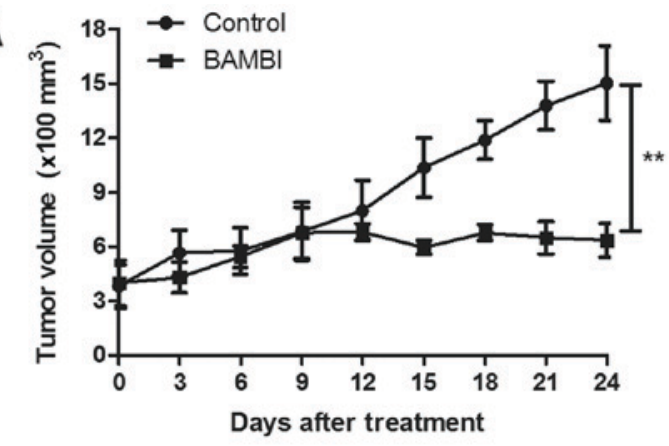

C

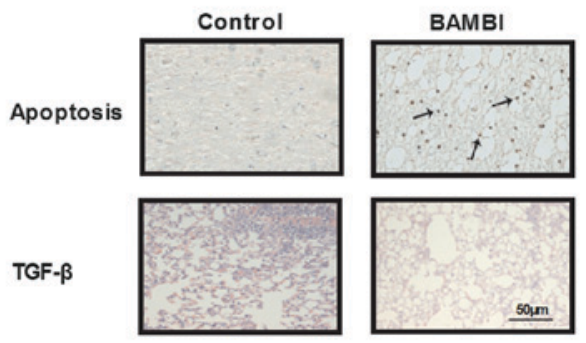

$\mathbf{E}$

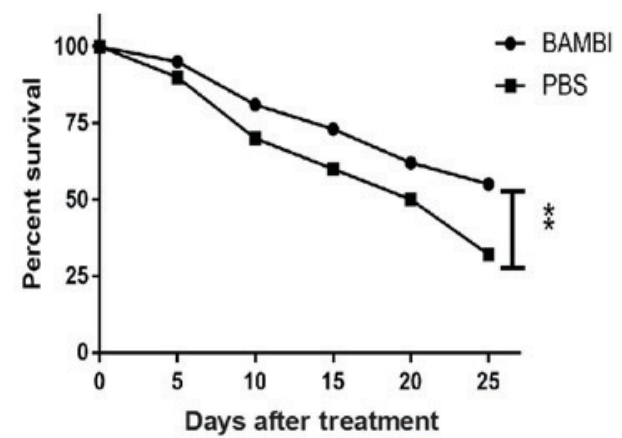

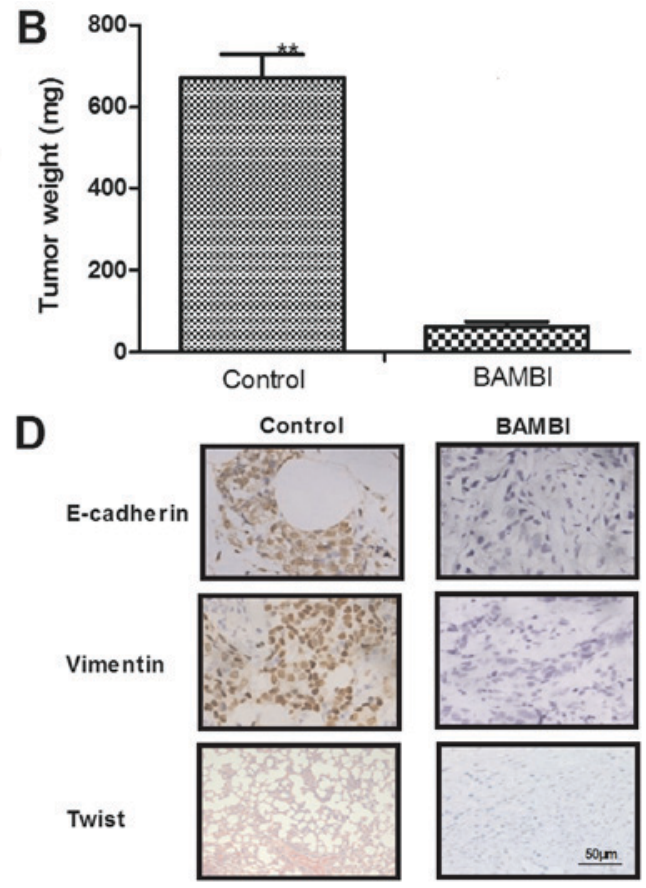

Figure 5. In vivo efficacy of BAMBI reconstitution in xenografted mice. (A) BAMBI treatment significantly suppressed osteosarcoma growth. (B) BAMBI treatment significantly decreased osteosarcoma weight. (C) BAMBI treatment increased the number of apoptotic cells and decreased the TGF- $\beta$ expression in tumor sections (magnification, x200). (D) BAMBI treatment downregulated EMT markers E-cadherin, vimentin and Twist expression in tumor sections (magnification, x200). (E) Evaluation of the median overall survival of xenografted mice. ${ }^{* *} \mathrm{P}<0.01$ vs. control group. E-cadherin, epithelial-cadherin; BAMBI, bone morphogenetic protein and activin membrane-bound inhibitor; TGF- $\beta$, transforming growth factor- $\beta$; EMT, epithelial-to-mesenchymal transition.

E-cadherin and inhibited vimentin and Twist expression in SAOS2 and MG63 cells (Fig. 4B). Results demonstrated that expression and phosphorylation levels of Smad2 and Smad3 were decreased by BAMBI treatment in SAOS2 and MG63 cells (Fig. 4C). It was determined that the blocked TGF- $\beta$ receptor using SB431542 also suppressed the expression and phosphorylation levels of Smad 2 and Smad3 in BAMBI-treated SAOS2 and MG63 cells (Fig. 4D); however, pTGF- $\beta$ antagonized the expression and phosphorylation of Smad2 and Smad3, as well as EMT markers in BAMBI-treated SAOS2 and MG63 cells (Fig. 4E and F). Notably, it was determined that pTGF- $\beta$ inhibited BAMBI-inhibited growth and invasion of SAOS2 and MG63 cells (Fig. 4G and H). Collectively, the results indicated that $\mathrm{BAMBI}$ reconstitution inhibits osteosarcoma growth and invasion via inactivating the TGF- $\beta$-induced EMT signaling pathway.

In vivo efficacy of $B A M B I$. To further identify the therapeutic efficacy of BAMBI for osteosarcoma growth, osteosarcoma xenograft mice model were established. The results demonstrated that the intratumor injection of BAMBI
(10 $\mathrm{mg} / \mathrm{ml})$ significantly inhibited tumor growth and tumor weight, compared with PBS-treated group (Fig. 5A and B; $\mathrm{P}<0.05)$. The TUNEL assay demonstrated that BAMBI increased apoptotic cells and decreased TGF- $\beta$ expression in the tumor sections, compared with control group (Fig. 5C). Immunohistochemistry indicated that EMT markers were decreased in BAMBI-treated tumor tissues, compared with control (Fig. 5D). Collectively, these results indicated that BAMBI may be a potential anticancer agent for osteosarcoma and improve the overall survival rate of xenografted mice compared with control group (Fig. 5E, $\mathrm{P}<0.05$ ).

\section{Discussion}

Osteosarcoma occurs in bones and their affiliated tissues; however, the mechanism underlying tumorigenesis remains unclear (22). The common symptoms of malignant osteosarcoma include: Bone pain; swelling; and fatigue $(23,24)$. Recently, numerous reports have proposed strategies for the treatment of osteosarcoma (25-27); however, the overall survival rate of patients with osteosarcoma has not significantly 
improved. A previous study determined that TGF- $\beta 1$ inhibitory pseudo-receptor-BAMBI may be regarded as a target in the $\beta$-catenin pathway of colorectal tumor cells, which further results in the inhibition of tumor cells growth and metastasis (28). Notably, the potential molecular mechanism mediated by BAMBI in the progression of osteosarcoma is not well understood. In the present study, the inhibitory effects of BAMBI on osteosarcoma cell growth was investigated in vitro and in vivo. The BAMBI-mediated signaling pathway in osteosarcoma cell lines SAOS2 and MG63 was analyzed. The data demonstrated that BAMBI expression is downregulated in osteosarcoma cell lines and BAMBI suppresses the growth and aggressiveness of osteosarcoma cell lines via the TGF- $\beta$-induced EMT signaling pathway.

Although a previous study indicated the role of BAMBI in gastric cells, very few studies focus on how BAMBI-mediated growth and metastasis of osteosarcoma cells (29). Notably, decreasing the BAMBI expression enhanced TGF- $\beta$ signaling and invasion in NSCLC cells (15). In the present study, a lower expression of BAMBI was observed in osteosarcoma cells following TGF- $\beta$-induced aggression and EMT-dependent malignant processes (30). Although Zhou et al (31) indicated that BAMBI serves a key role in the pathogenesis and progression of osteosarcoma by regulating the expression of $\beta$-catenin and other signal molecules via the pathways involved in the regulation of the cell cycle, the results concluded conflicting results in human osteosarcoma. Our hypothesis was further identified in xenografted mice and indicated that BAMBI treatment significantly inhibited osteosarcoma cells growth and promoted the apoptosis of tumor cells.

Previous reports have indicated that the TGF- $\beta$ and EMT signaling pathways are considered to be correlated with malignancy of osteosarcoma and responsible for its growth, migration and metastasis (32-35). Tsubaki et al (36) demonstrated that inhibition of the Ras/mitogen-activated protein kinase kinase/extracellular signal-regulated kinase and Ras/phosphoinositide 3-kinase/Akt pathways by reduction of the expression of TGF- $\beta$ could inhibit tumor growth in mouse osteosarcoma. Studies have indicated that the EMT signaling pathway serves a significant role in osteosarcoma and evidence indicated that overexpression of EMT transcription factors, including Twist, Snails and zinc finger E-box binding homeobox, is involved in the complex pathogenesis of osteosarcoma $(35,37)$. Furthermore, Wendt et al (38) indicated that deconstructing the mechanisms and consequences of TGF- $\beta$-induced EMT exerted anticancer activities by prohibiting cell proliferation. In the present study, the results indicated that BAMBI treatment suppresses growth and aggressiveness of osteosarcoma cell lines via the TGF- $\beta$-induced EMT signaling pathway, whilst TGF- $\beta$ overexpression antagonized the downregulated expression and phosphorylation of Smad2 and Smad3, as well as EMT markers caused by BAMBI treatment in SAOS2 and MG63 cells.

In conclusion, the data indicated that BAMBI treatment may result in the inhibition of SAOS2 and MG63 cells via regulation of the TGF- $\beta$-induced EMT signaling pathway, which contributes to increasing the apoptosis of tumor cells (39). Outcomes demonstrated that BAMBI treatment suppresses osteosarcoma cells in vitro and in vivo, which may enhance the therapeutic effects of BAMBI in the treatment of osteosarcoma. Notably, BAMBI treatment increases the apoptosis of osteosarcoma cells induced by cisplatin via inhibition of anti-apoptosis gene P16, P21 and Bcl-2 in SAOS2 and MG63 cells. In combination, these investigations indicate that BAMBI may be a potential agent for the treatment of osteosarcoma; however, future studies are required to investigate and identify the therapeutic effects of BAMBI in different osteosarcoma cell lines.

\section{Acknowledgements}

Not applicable.

\section{Funding}

No funding was received.

\section{Availability of data and materials}

The datasets used and/or analyzed during the current study are available from the corresponding author on reasonable request.

\section{Authors' contributions}

FL and KW designed the study. LZ and YY performed the experiments. YY analyzed the data.

\section{Ethics approval and consent to participate}

All patients were required to provide written informed consent prior to their inclusion. The study was approved by the Ethics Committee of The Second Hospital of Tianjin Medical University (Tianjin, China).

\section{Consent for publication}

All patients provided written informed consent for the publication of their data.

\section{Competing interests}

The authors declare that they have no competing interests.

\section{References}

1. Mathkour M, Garces J, Beard B, Bartholomew A, Sulaiman OA and Ware ML: Primary high-grade osteosarcoma of the clivus: A case report and literature review. World Neurosurg 89: 730.e9-730.e13, 2016.

2. Zheng YF, Lin J and Yang HL: Chondroblastic osteosarcoma secondary to fibrosarcoma: A case report and literature review. Oncol Lett 10: 3573-3576, 2015.

3. Friebele JC, Peck J, Pan X, Abdel-Rasoul M and Mayerson JL: Osteosarcoma: A meta-analysis and review of the literature. Am J Orthop (Belle Mead NJ) 44: 547-553, 2015.

4. Tsagaraki I, Tsilibary EC and Tzinia AK: TIMP-1 interaction with alphavbeta3 integrin confers resistance to human osteosarcoma cell line MG-63 against TNF- $\alpha$-induced apoptosis. Cell Tissue Res 342: 87-96, 2010.

5. Locklin RM, Federici E, Espina B, Hulley PA, Russell RG and Edwards CM: Selective targeting of death receptor 5 circumvents resistance of MG-63 osteosarcoma cells to TRAIL-induced apoptosis. Mol Cancer Ther 6: 3219-3228, 2007.

6. Dell'Amore A, Asadi N, Caroli G, Dolci G, Bini A and Stella F: Recurrent primary cardiac osteosarcoma: A case report and literature review. General Thorac Cardiovasc Surg 62: 175-180, 2014. 
7. Farcas N, Arzi B and Verstraete FJ: Oral and maxillofacial osteosarcoma in dogs: A review. Vet Comp Oncol 12: 169-180, 2014

8. Shangguan L, Ti X, Krause U, Hai B, Zhao Y, Yang Z and Liu F: Inhibition of TGF- $\beta /$ Smad signaling by BAMBI blocks differentiation of human mesenchymal stem cells to carcinoma-associated fibroblasts and abolishes their protumor effects. Stem Cells 30: 2810-2819, 2012

9. Guillot N, Kollins D, Gilbert V, Xavier S, Chen J, Gentle M, Reddy A, Bottinger E, Jiang R, Rastaldi MP, et al: BAMBI regulates angiogenesis and endothelial homeostasis through modulation of alternative TGF $\beta$ signaling. PloS one 7: e39406, 2012.

10. Fritzmann J, Morkel M, Besser D, Budczies J, Kosel F, Brembeck FH, Stein U, Fichtner I, Schlag PM and Birchmeier W: A colorectal cancer expression profile that includes transforming growth factor beta inhibitor BAMBI predicts metastatic potential. Gastroenterology 137: 165-175, 2009.

11. Khin SS, Kitazawa R, Win N, Aye TT, Mori K, Kondo T and Kitazawa S: BAMBI gene is epigenetically silenced in subset of high-grade bladder cancer. Int J Cancer 125: 328-338, 2009.

12. Miao S, Zhao L, Gao J, Wang H and Cui Z: Distribution and mRNA expression of BAMBI in non-small-cell lung cancer. Zhongguo Fei Ai Za Zhi 12: 203-207, 2009 (In Chinese).

13. Pils D, Wittinger M, Petz M, Gugerell A, Gregor W, Alfanz A, Horvat R, Braicu EI, Sehouli J, Zeillinger R, et al: BAMBI is overexpressed in ovarian cancer and co-translocates with Smads into the nucleus upon TGF-beta treatment. Gynecol Oncol 117: 189-197, 2010.

14. Liu K, Song X, Ma H, Liu L, Wen X, Yu J, Wang L and Hu S: Knockdown of BAMBI inhibits $\beta$-catenin and transforming growth factor $\beta$ to suppress metastasis of gastric cancer cells Mol Med Rep 10: 874-880, 2014.

15. Marwitz S, Depner S, Dvornikov D, Merkle R, Szczygieł M, Müller-Decker K, Lucarelli $P$, Wäsch $M$, Mairbäurl $H$, Rabe KF, et al: Downregulation of the TGF $\beta$ Pseudoreceptor BAMBI in non-small cell lung cancer enhances tgfbeta signaling and invasion. Cancer Res 76: 3785-3801, 2016.

16. Xing W, Zhigang W, Bing H, Haitao R, Pan L, Chuanshan X, Yuanyi $\mathrm{Z}$ and Ao L: Targeting an ultrasound contrast agent to folate receptors on ovarian cancer cells: Feasibility research for ultrasonic molecular imaging of tumor cells. J Ultrasound Med 29: 609-614, 2010.

17. Livak KJ and Schmittgen TD: Analysis of relative gene expression data using real-time quantitative PCR and the 2(-Delta Delta C(T)) method. Methods 25: 402-408, 2001.

18. Shi X, DiRenzo D, Guo LW, Franco SR, Wang B, Seedial S and Kent KC: TGF-beta/Smad3 stimulates stem cell/developmental gene expression and vascular smooth muscle cell de-differentiation. PloS One 9: e93995, 2014.

19. Renshaw A and Elsheikh TM: A validation study of the Focalpoint GS imaging system for gynecologic cytology screening. Cancer Cytopathol 121: 737-738, 2013

20. Bai FL, Yu YH, Tian H, Ren GP, Wang H, Zhou B, Han XH, Yu QZ and Li DS: Genetically engineered Newcastle disease virus expressing interleukin-2 and TNF-related apoptosis-inducing ligand for cancer therapy. Cancer Biol Ther 15: 1226-1238, 2014

21. Zhuang T, Djemil T, Qi P, Magnelli A, Stephans K, Videtic G and Xia P: Dose calculation differences between Monte Carlo and pencil beam depend on the tumor locations and volumes for lung stereotactic body radiation therapy. J Appl Clin Med Phys 14: 4011, 2013.

22. Durfee RA, Mohammed M and Luu HH: Review of osteosarcoma and current management. Rheumatol Ther 3: 221-243, 2016.

23. He F, Zhang W, Shen Y, Yu P, Bao Q, Wen J, Hu C and Qiu S: Effects of resection margins on local recurrence of osteosarcoma in extremity and pelvis: Systematic review and meta-analysis. Int J Surg 36: 283-292, 2016.
24. Heaton TE, Hammond WJ, Farber BA, Pallos V, Meyers PA, Chou AJ, Price AP and LaQuaglia MP: A 20 -year retrospective analysis of CT-based pre-operative identification of pulmonary metastases in patients with osteosarcoma: A single-center review. J Pediatr Surg 52: 115-119, 2017.

25. Angelini A, Mavrogenis AF, Trovarelli G, Ferrari S, Picci P and Ruggieri P: Telangiectatic osteosarcoma: A review of 87 cases. J Cancer Res Clin Oncol 142: 2197-2207, 2016.

26. Bilbao-Aldaiturriaga N, Askaiturrieta Z, Granado-Tajada I, Goričar K, Dolžan V, For The Slovenian Osteosarcoma Study Group, Garcia-Miguel P; Garcia de Andoin N, Martin-Guerrero I and Garcia-Orad A: A systematic review and meta-analysis of MDM2 polymorphisms in osteosarcoma susceptibility. Pediatr Res 80: 472-479, 2016.

27. $\mathrm{Hu} \mathrm{K}$, Dai HB and Qiu ZL: mTOR signaling in osteosarcoma: Oncogenesis and therapeutic aspects (Review). Oncol Rep 36: 1219-1225, 2016

28. Sekiya T, Adachi S, Kohu K, Yamada T, Higuchi O, Furukawa Y, Nakamura $\mathrm{Y}$, Nakamura $\mathrm{T}$, Tashiro $\mathrm{K}$, Kuhara $\mathrm{S}$, et al: Identification of BMP and activin membrane-bound inhibitor (BAMBI), an inhibitor of transforming growth factor-beta signaling, as a target of the beta-catenin pathway in colorectal tumor cells. J Biol Chem 279: 6840-6846, 2004.

29. Pak KH, Kim DH, Kim H, Lee do H and Cheong JH: Differences in TGF- $\beta 1$ signaling and clinicopathologic characteristics of histologic subtypes of gastric cancer. BMC Cancer 16: 60, 2016.

30. Cho Y, Cho EJ, Lee JH, Yu SJ, Kim YJ, Kim CY and Yoon JH: Hypoxia enhances tumor-stroma crosstalk that drives the progression of hepatocellular carcinoma. Dig Dis Sci 61: 2568-2577, 2016.

31. Zhou L, Park J, Jang KY, Park HS, Wagle S, Yang KH, Lee KB, Park BH and Kim JR: The overexpression of BAMBI and its involvement in the growth and invasion of human osteosarcoma cells. Oncol Rep 30: 1315-1322, 2013.

32. Tu B, Peng ZX, Fan QM, Du L, Yan W and Tang TT: Osteosarcoma cells promote the production of pro-tumor cytokines in mesenchymal stem cells by inhibiting their osteogenic differentiation through the TGF- $\beta /$ Smad $2 / 3$ pathway. Exp Cell Res 320: 164-173, 2014

33. Schedlich LJ, Yenson VM and Baxter RC: TGF- $\beta$-induced expression of IGFBP-3 regulates IGF1R signaling in human osteosarcoma cells. Mol Cell Endocrinol 377: 56-64, 2013.

34. Yu L, Liu S, Guo W, Zhang C, Zhang B, Yan H and Wu Z: hTERT promoter activity identifies osteosarcoma cells with increased EMT characteristics. Oncol Lett 7: 239-244, 2014

35. Yang G, Yuan J and Li K: EMT transcription factors: Implication in osteosarcoma. Med Oncol 30: 697, 2013

36. Tsubaki M, Yamazoe Y, Yanae M, Satou T, Itoh T, Kaneko J, Kidera Y, Moriyama K and Nishida S: Blockade of the Ras/MEK/ERK and Ras/PI3K/Akt pathways by statins reduces the expression of bFGF, HGF and TGF- $\beta$ as angiogenic factors in mouse osteosarcoma. Cytokine 54: 100-107, 2011.

37. Zhang D, Jiang F, Wang X and Li G: Downregulation of ubiquitin-specific protease 22 inhibits proliferation, invasion and EMT in osteosarcoma cells. Oncol Res 25: 743-751, 2016.

38. Wendt MK, Tian M and Schiemann WP: Deconstructing the mechanisms and consequences of TGF- $\beta$-induced EMT during cancer progression. Cell Tissue Res 347: 85-101, 2012.

39. Kitazawa S, Kitazawa R, Obayashi C and Yamamoto T: Desmoid tumor with ossification in chest wall: Possible involvement of BAMBI promoter hypermethylation in metaplastic bone formation. J Bone Miner Res 20: 1472-1477, 2005.

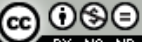

This work is licensed under a Creative Commons Attribution-NonCommercial-NoDerivatives 4.0 International (CC BY-NC-ND 4.0) License. 